\title{
Global Climate Change: Assessing the Importance of the Roles of Ice Cover and Glacial Changes
}

\author{
E. A. McBean ${ }^{1 *}$ \\ ${ }^{1}$ School of Engineering, University of Guelph, Guelph, ON N1G 2W1, Canada
}

Received 27 March 2021; revised 17 May 2021; accepted 24 May 2021; published online 30 June 2021

\begin{abstract}
Issues of water security are rapidly becoming more widely recognized as impacted. Increased levels of carbon dioxide are clearly evident and long-term temperature increases are clearly evident. These indicators are being used to compile evidence that sea level rise in the future will be between 0.3 and $1.0 \mathrm{~m}$ by 2100 and, combined with more severe storms along coastlines, will translate into increasing challenges for coastal cities. The enormous glaciers in Greenland and Antarctica will continue to contribute to sea level rise but fortunately, at modest levels, for thousands of years. On the other hand, land-based glaciers will continue to become depleted and the ramifications to agricultural practices are expected to be profound, with situations of significant percentages of the world's landbased glaciers being lost by 2100. Further, the disappearance rate of the Arctic Ocean ice cover is already profoundly evident, with los ses of ice cover of about 13.1 percent per decade now occurring. Rates of warming in the Arctic are increasing at two to three times the global annual average and warrant further forecasting of the implications. With the reduced ice cover, the water in the Arctic Ocean is now absorbing the energy from the sun, not reflecting the sun's energy, thereby accelerating further ice cover melting. The result is that the jet stream is weakening and evidence is mounting that there will be increased excursions of the polar vortex causing very cold weather extremes in northern hemisphere areas.
\end{abstract}

Keywords: climate change, Arctic Ocean, polar vortex, sea level rise, glaciers, land-based glaciers

\section{Introduction}

Issues of water security and the implications of ongoing climate change are profound, and intensifying. Evidence of climate change is widespread and sporadic, including many dimensions including intense rainfall events, destructive storm surges, and the growing scarcity of accessible potable water. As an indication of changing circumstances, although the overall number of hurricanes has remained roughly the same during recent decades, there is evidence that hurricanes are intensifying more quickly, resulting in greater numbers of the most severe category of four and five storms (see Figure 1). The recordbreaking 2020 hurricane season in the US produced 30 named storms and the 2020 Atlantic hurricane season also broke records as Tropical Storm Edouard formed as the earliest 5 th named Atlantic storm on record (Sassian, 2020).

A further complication for water security is that while the world's population has doubled over the last fifty years, water use has tripled; there is not sufficient water for that opportunity to be available again. As an indication of how complicated this problem is becoming, the findings in a case study in the Zabezi River basin in Africa indicate that while future climate change

${ }^{*}$ Corresponding author. Tel.: +1 519824 4120-53923.

E-mail address: emcbean@uoguelph.ca (E. A. McBean).

ISSN: 2663-6859 print/2663-6867 online

(C) 2021 ISEIS All rights reserved. doi:10.3808/jeil.202100061. is projected as $25 \%$ of the impact to future water scarcity in the Zambezi watershed, $75 \%$ of the impending water scarcity in the Zambezi is attributable to expected population increases (and its related food, energy, and changing dietary habits), showing that population increases also represent an important threat to water security (McBean, 2017). With projections indicating that the global population will reach 10 billion people by 2060 (UN Population Division, 2019), this further complicates the challenges that $10.9 \%$ of the human population live in coastal zones. That percentage is projected to increase to $12 \%$ (a larger percentage of a larger population in 2060), indicating the risks are intensifying (Neumann et al., 2015). These and many more issues are resulting in water security issues becoming increasingly challenging.

Other dimensions demonstrating intensifying water security conditions include extraction of groundwater to respond to the needs for water supplies to megacities, are resulting in significant land subsidence. Particularly relevant is since most of the world's megacities are located in coastal zones (Brown et al., 2013) and many are situated in large deltas. Megacities are acting as gateways to the global economy but also, subject to sea level rise, land subsidence through groundwater extraction, and hurricanes/typhoons (McBean and Huang, 2020).

While the preceding examples represent just a few of the widespread challenges of water security, there are definite limits to our understanding of the degree to which individual aspects of climate change are influenced by, and influencing to, key 
features. In particular, the roles of glaciers, and rates of depletion of ice cover on the Arctic Ocean are now increasingly being assessed for their potentially important roles in influencing the Earth's rate of climate change. With the intent of gaining an improved understanding of important historical influences changing water security, and information which continues to be assembled, this paper focuses on prioritizing a number of specific issues needing understanding as climate change on Earth continues to evolve.

\section{Unpredictable Danger: Hurricane Seasons Since 1967}

Number of tropical cyclones over the Atlantic basin 1967-2019, by Saffir-Simpson scale category
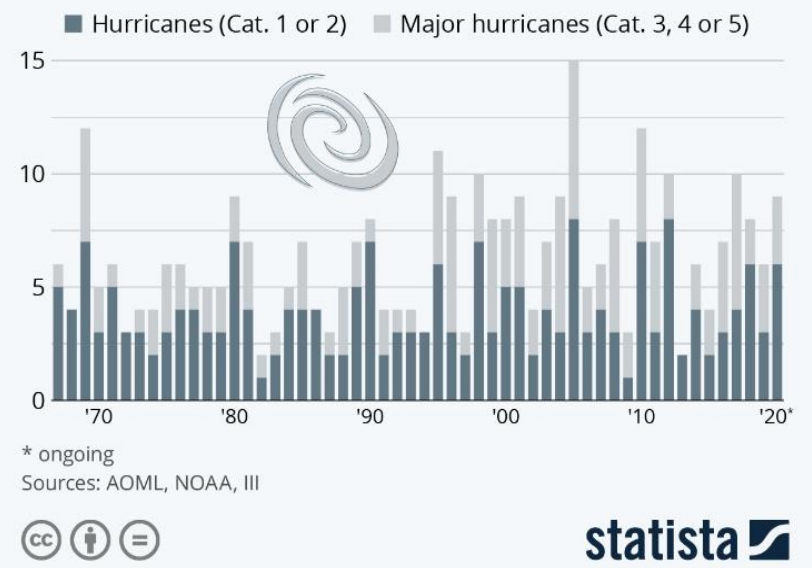

Figure 1. Hurricanes-Over-the-Atlantic Basin (Statista.com, 2021).

\section{Examples of Indicators Showing Intensifying Climate Change Concerns}

\subsection{Overview of Classes of Features Showing Intensification of Climate Change}

Issues of intensifying climate change are substantial individually but the need exists to collectively assess different dimensions to provide an overall assessment due to their individuality. An overall assessment must rely upon various types of indicators since no single indicator is, by itself sufficiently rigorous to indicate the breadth of climate change impacts. Hence, the next four subsections each describe individual domains of information, all contributing to assist in arriving at conclusions. The first segment briefly indicates the role of the earth's periodic ice ages, and subsequently, the roles of the polar glaciers, influencing sea level rise. While these two segments focus on sea level rise, the third segment describes a very different dimension which is expected to cause enormous challenges due to landbased glaciers melting, but the most poorly understood and one of the most important dimensions of climate change, is the possible result of the melting of Artic Ocean snow and ice cover, and the influence of the troposphere in impacting the climate.

\subsection{Implications of Ice Age Timing on Sea Level Changes}

The world's most recent ice age was completed approximately 8,000 years ago. For the preceding period, from 14,000 to 8,000 years ago, huge changes in sea levels $(\sim 120 \mathrm{~m})$ took place, due to the melting of the glacial ice on land (see Figure 2). Then, from 8000 years ago to the present time, the rate of increase in sea level has been characterized as much lower, at the rate of $\sim 1.3 \mathrm{~mm} /$ year (Hünicke et al., 2015), arising from consequences such as the continued melting of land glaciers as well as the thermal expansion of the oceans. As a specific indicator of the future, the IPCC $5^{\text {th }}$ Assessment report (IPCC, 2013), predicts that thermal expansion and land-based glacier melting moving forward in time are projected to translate to relatively low rates of sea level increase, at between 2.6 to 9.8 $\mathrm{mm} /$ year, meaning sea level rise is projected to increase between 0.3 and $1.0 \mathrm{~m}$ by the year 2100 (IPCC, 2013).

Potentially influencing whether the relatively modest increase in sea level over the last 8000 years as predicted depends on whether another ice age begins. It is relevant to note that there is significant evidence that if climate conditions were not being disrupted by human activities, the world would likely be in the beginning stages of another ice age. The Earth's wobbly rotation is considered the likely cause of periodic ice ages with the Earth's mildly eccentric orbit around the sun being the pacemaker of great ice ages (Weisman, 2007). Individually, glacial ages have lasted upwards of 100,000 years, with intervening thaws averaging from 12,000 to 28,000 years (Weisman, 2007). For the last few million years, the continents have remained essentially where they exist today, and glacial ages have recurred quite regularly. However, the consensus is that the Earth appears to be in an interglacial period, and as will be demonstrateed below, the Earth's atmosphere is warming.

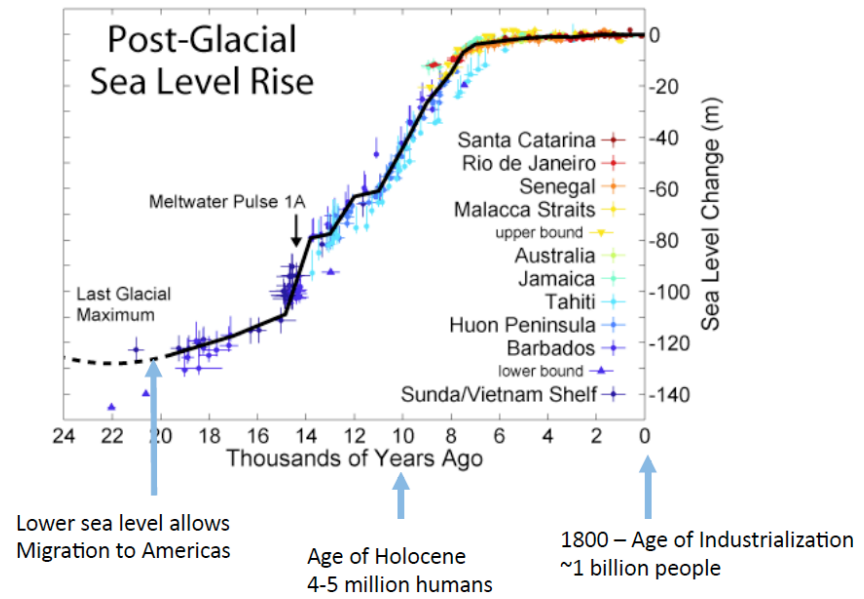

Figure 2. Post - Glacial Sea Level Rise. (Reference: Adapted from Wikipedia. Sea Level Rise, accessed November 8, 2016 - This figure was prepared by Robert A. Rohde from published data, and is incorporated into the Global Warming Art project).

To understand the background as to why the Earth's atmosphere is warming, consider the historical accounts of gradual swings in carbon dioxide concentrations that have been thor- 
oughly researched and are now well-established (e.g., see Hayset al., 1976; Maslin, 2016). As shown in Past Global Changes (2021), the atmospheric carbon dioxide levels have increased from 180 to 220 ppmv from 20 thousand years ago, then increased substantially from 20 thousand years ago to $280 \mathrm{ppmv}$ to about 1,000 years ago to more than $400 \mathrm{ppmv}$, and now, $\mathrm{CO}_{2}$ concentrations are consistently more than $1,000 \mathrm{ppmv}$. With the current situation of humans extracting so much of the carboniferous deposits (e.g., oil and gases) that accumulated over millennia around the world, and releasing the carbon dioxide into the atmosphere, human activities are releasing massive amounts of carbon dioxide to the atmosphere (5 to 8 times the rate of carbon dioxide released during the Eocene) (McBean and Huang, 2020). The $\mathrm{CO}_{2}$ levels are now continuing to dramatically increase and it is now widely accepted that humans have caused this acceleration in $\mathrm{CO}_{2}$ levels, and that ongoing global environmental impact is occurring due to anthropogeniccaused (i.e., human-caused) climate change. Related projections are for increasing greenhouse gas concentrations in the atmosphere and increasing temperatures, year over year. The warmest temperatures in decades, with global temperatures increasing from 1880 to 2019, are showing increasing levels as evident in a global land-ocean temperature index by NASA (NASA Global, 2021). These results show temperatures have demonstrated progressive increase over the past 140 years (see Figure 3 ).

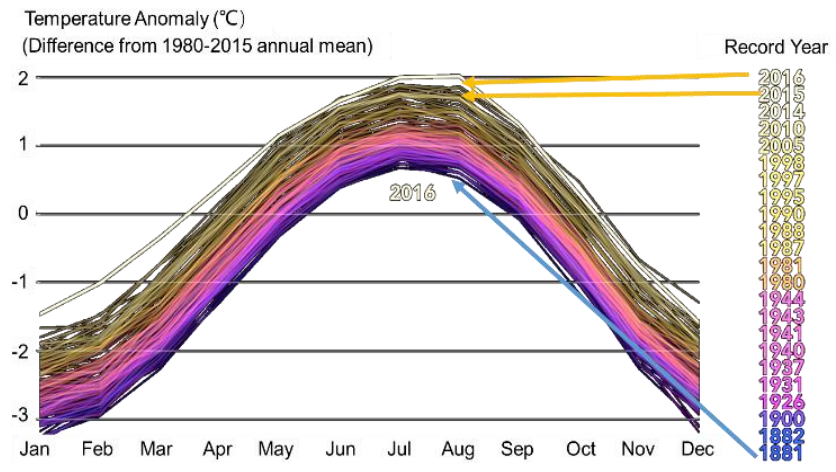

Figure 3. Temperature differences from $1980 \sim 2016$ (as modified background from NASA, 2017).

Given the supporting rationale which is now being widely accepted as causing the relatively low rate of change of sea level (i.e., extending the sea level elevations into the future, from those indicated in Figure 2), concerns are focusing on the implications to rainfall rates. Specifically, the impacts of global temperatures have been assessed using the Clausius-Clapyron equation showing that the water-holding capacity of the Earth's atmosphere increases by $7 \%$ per ${ }^{\circ} \mathrm{C}$ of increase (RNMI, 2009). Hence, from NASA (2017), the temperature anomaly (from Figure 3 ) indicates that the annual mean temperature difference from $1980 \sim 2016$ is $1{ }^{\circ} \mathrm{C}$ from 2005 to 2016, there are bases for interpreting there is increased moisture in the atmosphere, more energy, and more intense storms as are being reported (see e.g., Martinkova and Kysely, 2020; Sen Roy and Roy, 2021; Vergara-Temprado et al., 2021).

As a result, there is general agreement that sea levels will increase by 0.3 to $1 \mathrm{~m}$ by year 2100 , and hence problematic, and coastal cities will continue to be hit by increasing typhoons /hurricanes, and some small island countries will be submerged causing devastation, and the need for more protective measures to control coastal flooding (e.g., see McBean and Huang (2020) for examples of possible actions).

\subsection{Assessment Whether Polar Glaciers Are Likely to Melt}

An indication of the importance of polar glaciers is needed, to establish context. The Antarctic and Greenland ice sheets are enormous. If total melting of these polar glaciers were to occur, the consequences would be catastrophic, as Greenland and Antarctica are home to most of the world's glacial ice. These thick slabs of ice, namely 3,000 and 4,500 m thick on average, respectively, contain most of the freshwater on Earth. Combined, the two regions contain sufficient ice that, if melted, ocean levels would rise by nearly $65 \mathrm{~m}$, making the understanding of these glaciers not just interesting, but crucial to the world's adaptability/survival.

Current estimates of the mass loss from the Greenland Ice Sheet and Antarctica contribute at this time around 25 and 10 percent, respectively, of the global sea level rise of about 3 $\mathrm{mm} /$ year (Schmith and Tonboe, 2009). Even a small percentage of melting of the polar ice cap in Antarctica would be catastrophic but that won't happen for thousands of years (McBean and Huang, 2017). Levermann et al. (2013) indicate that over thousands of years, the Antarctic ice sheets will contribute 1.2 $\mathrm{m}$ of sea level rise per degree of warming. For warming between $2 \sim 4{ }^{\circ} \mathrm{C}$, the Greenland Ice Sheet will contribute $0.34 \mathrm{~m}$ of sea level rise per degree of warming, and it has a total sea level contribution of up to $6 \mathrm{~m}$ (Schmitch and Tonboe, 2009). The result is that polar glacier melting for Greenland and Antarctica will be continuing to add to sea level rise but at relatively small levels for the next century.

\subsection{Implications of Melting Land-Based Glaciers}

A very different concern from the issue in Section 2.2 is the degree to which land-based glaciers are expected to dissipate with time. There are about 198,000 land glaciers in the world, covering $726,000 \mathrm{~km}^{2}$, and $0.5 \%$ of the Earth's land surface excluding the large Antarctic and Greenland ice sheets (Davies, 2021). However, the sea-level equivalent of all the landbased glaciers in the world is only $0.41 \mathrm{~m}$, which means that land-based glaciers' contributions represent only a portion of the expansion of the ocean (Davies, 2021). Together with the Antarctic and Greenland ice sheets, land glaciers cover approximately 10 percent of the land (about 16 million $\mathrm{km}^{2}$ ) (NSIDC, 2017). To put these magnitudes in context, during the most recent Ice Age, glacier coverage was substantially larger, at 32\% of the land (NSIDC, 2017).

While the long-term contributions to global sea level rise are eventually limited by the relatively small volume of ice contained in the land-based glaciers, their importance to global populations are enormous since their current melting augments the available fresh water otherwise available for use by the human population. These land-based glaciers have short response 


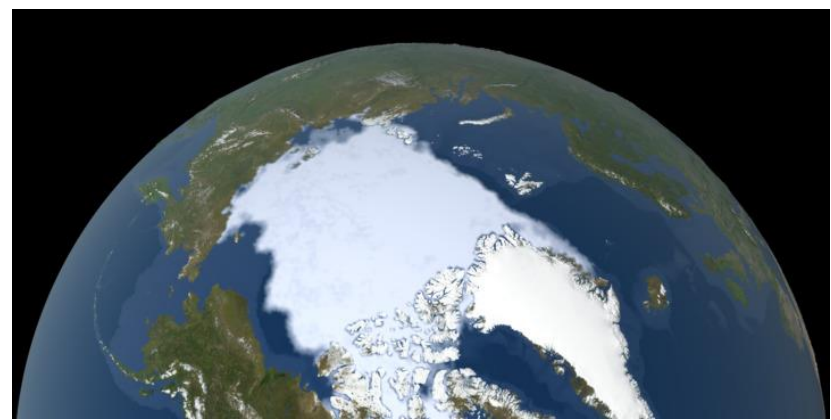

(a) Arctic Sea Ice 1979

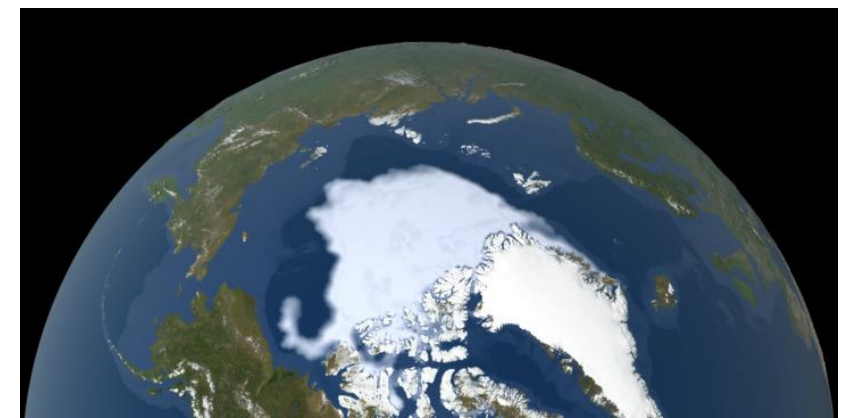

(b) Arctic Sea Ice 2020

Figure 4. Arctic sea changing over time (Ref. data source: Satellite observations; credit "NASA scientific visualization studio").

times (Note, this statement does not include the Hindu Kush Himalayan (HKH) mountain glaciers in Afghanistan, the socalled "water tower for Asia" which contains a significant portion of the world's land-based glacier water (Scott et al., 2019; Taraky et al., 2021). Hence, for all the land-based glaciers in absence of the noted HKH exception, react quickly to climate change and are currently contributing about one-third of the currently observed sea level rise; as a result, the contributions from land-based glaciers are more important than the Antarctic and Greenland ice sheets on decadal timescales. The importance of the land-based glacier contributions are, however, very important and the acceleration of the melting of the remaining glaciers and sea level increases in that the depletion of the land glaciers will have devastating consequences for the millions of people who rely on melting from these glaciers to provide freshwater, as they buffer the effects of seasonal precipitation regimes. Loss of land-based glacier melt will drive many agricultural areas into terrible situations, as the melting glaciers disappear.

The loss of these land-based glaciers will dramatically increase glacier hazards associated with glacier recession. Tourism and economies will be hit as land glaciers shrink. It is noted that, as a specific example, Canada is home to a significant percentage of the world's land-based glaciers and by 2100 , scientists predict that those in Alberta and British Columbia will have lost 70 per cent of their 2005 volume due to climate change (Rutter and Baker, 2018). The net result is the loss of land-based glaciers will not have large implications to sea level rise but will certainly cause enormous impacts to the availability of freshwater on the continents themselves.

\subsection{Role of Ice Cover on the Arctic Ocean}

The third aspect of glaciers and water availability, one which has not received the attention that is warranted, is in relation to the Arctic Ocean, and the effects of climate change. The Arctic Ocean is increasingly being considered as having an enormous role on the rate of global warming with recognition that climate change is not only a polar issue, but a global issue, and will require global solutions (Mernild, 2009).

Changes in climate have been greatest in the Arctic as dwindling amounts of snow and ice cover enhance the effects of warming. Arctic Ocean ice cover changes show the substantial change over time (see Figure 4). Ice has a high albedo mean- ing that because ice is white and highly reflective, it reflects incoming energy in the form of solar radiation. As the ice melts, the underlying and much darker seawater absorbs much more solar radiation, becomes warmer, and will be heating the atmosphere. Hence, the issue of the northern pole is the reflectivity rapidly evolving to become more open water, not ice cover which influences the radiation level. Due to the ice-albedo feedback, sea ice is an important factor for how much the global climate system changes. Thus, reduced ice cover leads to higher water temperatures which in turn, lead to even less ice cover with time (as apparent in Figure 4). The melting rate is compounded by the fact that winters in the Arctic (i.e., during winter when the Earth is closer to the Sun than during summer) are shorter than summers.

While the Northwest Passage was fervently pursued in historical times where the interest was to provide trade access between Europe and Asia, the Northwest Passage was impenetrable due to the ice cover on the Arctic Ocean. However, those times have changed. The extent of ice cover on the Arctic Ocean has undergone dramatic changes (see Figure 4) which illustrates the declining extent of ice cover on the Arctic Ocean, (NASA Arctic, 2012). Ice thickness at the North Pole is about $2 \sim 3$ meters and while there are areas with ice thickness up to $5 \mathrm{~m}$, sufficient amounts now have melted that the northwest passage is now open during summer periods (National Snow \& Ice Data Center, 2021). Arctic sea ice reaches its minimum each September and is now declining at a rate of 13.1 percent per decade, relative to the 1981 to 2010 average, an area equivalent to that of Denmark (almost $43500 \mathrm{~km}^{2}$ ) each year (Schmitch and Tonboe, 2009). Figure 4 shows the Arctic sea ice extent from 1979 to 2020 , derived from satellite observations (NASA Arctic, 2021).

Warming in the Arctic is changing at greater rates than the global annual average, at rates that are two to three times higher in the Arctic (IPCC, 2018). With dwindling amounts of snow and ice cover, the effects of warming and the spatial extent of ice cover disappearing rapidly, cruise ships are now passing through the northern passageway. Arctic cruiseline business is dramatically increasing and hence, what was infeasible one hundred years ago, cruiseline passage is now readily available; 239 different cruiseline vessels made that passage by March 17, 2020 (Headland, 2021).

A snow/ice-covered surface reflects massive amounts of 
sunlight and therefore, has a cooling effect on the climate. However, with increasing greenhouse gases, the Arctic warms more because the troposphere is thinner at the North Pole, and the reduced snow/ice cover and sea ice leads to less reflection of the sun's rays, resulting in the water now absorbing the energy from the sun, causing more ice cover melting. As the Earth's surface warms, there is more energy emitted back to space. However, less energy is radiated back from the Arctic compared to lower latitudes, meaning the Arctic warms more quickly.

\section{Polar Vortex}

While the previous section refers to specific dimensions of glaciers and Arctic Oean snow/ice cover, an additional dimension to understand how the role of snow and ice cover in the Arctic Ocean will translate to being referred to as causing polar vortices which are influencing the winter climate in the northern hemisphere. However, before the polar vortex can be described, it is essential to first describe the impacts of loss of ice/snow cover on the Arctic Ocean, the warming of the Arctic Ocean water, and the role of the troposphere.

The stratosphere is the upper middle part of the atmosphere, and is the level containing the Jet Stream winds. The troposphere is the lowest layer of the earth's atmosphere where most clouds appear in the troposphere ( $\sim 99 \%$ of the water vapor in the atmosphere is found in the troposphere). The average height of the troposphere is $18 \mathrm{~km}$ in the tropics, $17 \mathrm{~km}$ in the mid-latitudes, but only $6 \mathrm{~km}$ in the polar regions in winter (and hence, much thinner in the polar region). Unlike the troposphere, temperatures in the stratosphere increase with elevation. The trend of rising temperatures with altitude means that air in the stratosphere lacks the turbulence and updrafts of the troposphere beneath.
The so-called "polar vortex" is not a new concept but will become much more familiar with time as vortices are responsible for the dramatic, short-term changes in the winter climate which are increasingly present. Specifically, the term "vortex" refers to the counter-clockwise flow of air that helps retain the bitterly cold air near the Poles. The polar vortex is a large area of low pressure and cold air surrounding both poles of the Earth (see Figure 5 depicting this situation for the northern hemisphere). The Jet Stream winds tend to keep the bitter cold air locked in the Arctic. However, with rising temperatures in the Arctic, less reflected sunlight, and evaporation and transpiration increases, the polar vortex weakens or collapses. With large pockets of frigid air in combination with a weakening of the Jet Stream, the result is the circulation dipping south with the "wavy" character indicated in Figure 5. The strength of containment diminishes, loses strength, and the vortex slips or expands. The altering of the pressure and the temperature gradients of the polar vortex cause the weakening or collapse, creating the waving pattern. The result is that weather extremes enter areas outside (south of) the North Pole.

Due to these circumstances, the Arctic is warming more than twice as rapidly as the global surface average (Cohen et al., 2014) where this phenomenon is known as "Arctic amplification". In summary, this stems from the rapid loss of sea ice cover in the region and resulting energy from the sun that would have been reflected away by the ice is instead absorbed by the ocean, causing further warming.

While the polar vortex as described above has been well documented and acknowledged as present for a long while, its behavior has become more extreme as a result of climate change (Shepherd, 2021). The warming has led to the loss of Arctic sea ice, transforming a highly reflective icy surface to a dark absorptive surface. The change is warming higher latitudes and

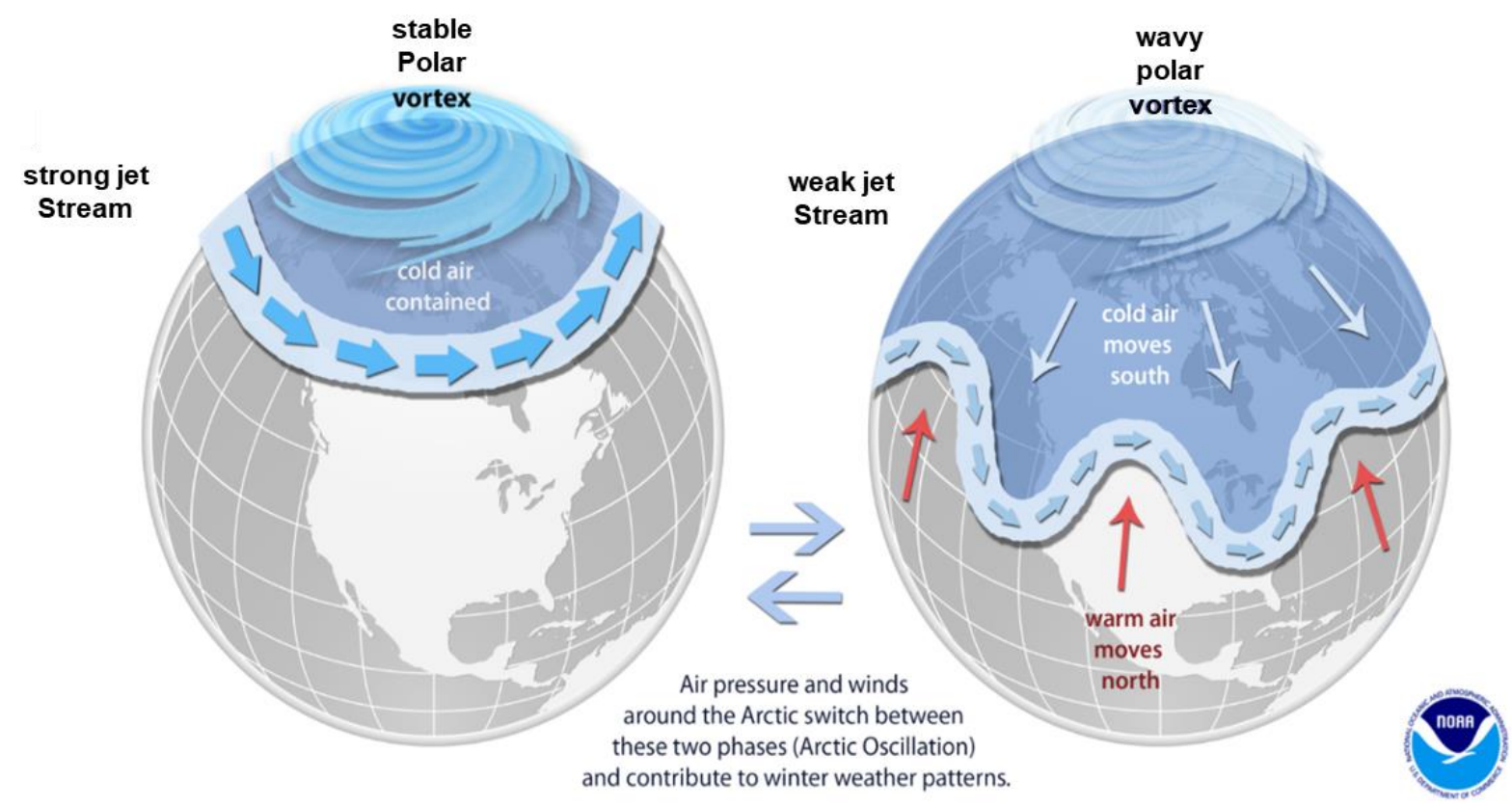

Figure 5. Depiction of polar vortex for stable and wavy situations (NOAA, 2021). 
reducing the temperature difference between the warmer midlatitude and polar regions. Future climate change is likely to further weaken the polar jet stream, bringing rise to even more extreme and unusual weather patterns (L'Heureux, 2021).

The result of a weakened polar vortex is causing migration south, bringing cold air with the vortex. As a result, there are more intensive storms, and more water as warmer air is much more effective at holding water, than is cold air. An example is the major vortex effect which "shut down" Houston in February 2021. The polar air masses migrating south left 4 million people in Houston, the US's fifth largest city, without power and water for days, in a city where snow doesn't happen typically happen every winter. With the polar vortex, a major snowstorm hit the US with some areas receiving more than $0.6 \mathrm{~m}$ of snow, as well, Spain experienced a historic snowstorm and some Siberian cities reported storms below $-70^{\circ} \mathrm{C}$, and snowfall happened in San Diego in early March 2021. The need to forecast and anticipate these types of frigid conditions is obviously important.

\section{Summary Thinking}

This final segment is intentionally not entitled "conclusions" because much remains to be learned and all that we understand now are "directions of change" but these directions and magnitudes need to be evaluated. Water security issues are clearly complicated and from the array of dimensions reflected upon within the preceding text, the future water security of the planet with climate change, population growth and human behavior is clearly going to become more challenging.

Basically, the points of summary thinking include:

(i) Climate change can be expected to increase the amount of water movement in the hydrologic cycle, which will include intensification of the hydrologic cycle, lesser rates of groundwater infiltration, increasing evapotranspiration, and increased air temperatures. All of these will introduce major challenges to the nexus of water security and the world's population;

(ii) The rate of rise of sea level will continue as a definite indicator of climate change. The projected increases in sea levels during the next century are expected to be (on average) between 0.3 and $1.0 \mathrm{~m}$ from current conditions. Storm surge and damage to coastal cities will continue to impact populations at risk, and actions to improve the resilience of coastal protection activities must be commenced, with no individual actions being sufficient by themselves. Some of the increases in sea levels are occurring due to melting of polar glaciers, continued melting of land-glaciers, and thermal expansion of the oceans due to increasing temperatures;

(iii) The melting of many land-based glaciers will be catastrophic for many regions around the globe as many of the land-based glaciers continue toward extinction; and,

(iv) Arctic Ocean ice cover will continue to be depleted. While the loss of Arctic Ocean ice cover will continue, the North Pole area will continue to warm, but the impacts on global climate change need to be better understood. There is in- creasing evidence that the rates of change are critical but not well quantified and not understood as to the implications to areas beyond the North Pole. The changes in temperature will influence winter weather patterns, including more frequent vortex weakening and slippage, with extreme cold periods impacting land masses substantially, to areas within the northern hemisphere.

The most important message from this research is that water security is destined to increase in severity throughout the world. World populations must use water very wisely in the future, and identify ways to do more, with less.

Acknowledgments. Funding from NSERC Discovery (400677) and the University of Guelph Leadership Chair are gratefully acknowledged, as contributing to the development of this paper.

\section{References}

Brown, S., Nicholls, R., Woodroffe, C., Hanson, S., Hinkel, J., Kebede, A.S., Neumann, B., and Vafeidis, A. (2013). Sea-level rise impacts and responses: A global perspective. Coastal Hazards. Springer, Netherlands, pp. 117-149. https://doi.org/10.1007/978-94007-5234-4_5

Cohen, J., Screen, J.A., Furtado, J.C., Barlow, M., Whittleson, D., Coumou, D., Francis, J., Dethloff, K., Entekhabi, D., Overland, J., and Jones, J. (2014). Recent Arctic amplification and extreme midlatitude weather. Nature Geoscience. 7, 627-637. https://doi. org/10.10 38/ngeo2234

Davies, B. (2020). Mapping the world's glaciers. http://www.ant arctic glaciers.org/glaciers-and-climate/glacier-recession/mapping -worlds-glaciers/

Hays J.D., Imbrie J. and Shackleton N.J. (1976). Variations in the earth's orbit: Pacemaker of the ice ages. Science, 194(4270), 11211132. https://doi.org/10.1126/science.194.4270.1121

Headland, R.K. Transits of the Northwest Passage to end of 2019 Navigation Season. Scott Polar Research Institute. https://www. spri.cam.ac.uk/resources/infosheets/northwestpassage.pdf (Accessed March 13, 2021)

Hünicke, B., Zorita, E., Soomere, T., Madsen, K.S., Johansson, M., and Suursaar, Ü. (2015). Recent change - sea level and wind waves. The BACC II Author Team (eds.). Second Assessment of Climate Change for the Baltic Sea Basin. Regional Climate Studies. Springer, pp 155-185.

IPCC (2013). Climate Change 2013: The Physical Science Basis. Contribution of Working Group I to the Fifth Assessment Report of the Intergovernmental Panel on Climate Change. Stocker, T.F., Qin, D., Plattner, G.-K., Tignor, M., Allen, S.K., Boschung, J., Nauels, A., Xia, Y., Bex, V., and Midgley, P.M. (eds.). Cambridge University Press, Cambridge, United Kingdom and New York, NY, USA, pp 1535. https://doi.org/10.1017/CBO9781107415324

IPCC (2018). Global Warming of $1.5^{\circ} \mathrm{C}$ : Summary for Policymakers. IPCC SR1.5.

IPCC (2018) Masson-Delmotte, V., P. Zhai, H.-O. Pörtner, D. Roberts, J. Skea, P.R. Shukla, A. Pirani, W. Moufouma-Okia, C. Péan, R. Pidcock, S. Connors, J.B.R. Matthews, Y. Chen, X. Zhou, M.I. Gomis, E. Lonnoy, T. Maycock, M. Tignor, and T. Waterfield (eds.) Summary for Policymakers. In: Global Warming of $1.5{ }^{\circ} \mathrm{C}$. An IPCC Special Report on the impacts of global warming of $1.5^{\circ} \mathrm{C}$ above pre-industrial levels and related global greenhouse gas emission pathways, in the context of strengthening the global response to the threat of climate change, sustainable development, and efforts to eradicate poverty. World Meteorological Organization, Geneva, Switzerland, pp 32. 
Levermann, A., Clark, P.U., Marzeion, B., Milne, G., Pollard, D., Radic, V., and Robinson, A. (2013). The multimillenial sea-level commitment of global warming. Proceedings of the National Academy of Sciences of the United States of America, 110(34), 1374513750. https://doi.org/10.1073/pnas.1219414110

Martinkova, M., and Kysely, J. (2020). Overview of observed Clausius-Clapeyron scaling of extreme precipitation in midlatitudes. Atmosphere, 11(786). https://doi.org/10.3390/atmos 11080786

Maslin, M. (2016). In retrospect: Forty years of linking orbits to ice ages. Nature, 540, 208-210. https://doi.org/10.1038/540208a

McBean, E. (2017). Water security, the nexus of water, food, population growth, and energy. The Global Environmental Engineers Journal, 3, 33-39. E-ISSN 2410-3624/16.

McBean, E. and Huang, J. (2020). Water security implications in the 21st century for coastal cities: The imperative need for action. Journal of Water Resources Planning and Management, 146(8), 0252003. https://doi.org/10.1061/(ASCE)WR.1943-5452.0001264

Mernild, S.H. (2009). The Polar Regions are melting - together, we can change the climate. Aktuel Naturvidenskab. www.aktuelnatur videnskab.dk

NASA (National Aeronautics and Space Administration). First 6 months of year warmest to date. http://www.growingproduce.com/ vegetables/nasa-first-6-months-of-year-warmest-to-date/ (accessed December 8, 2017).

NASA Arctic (2021). Arctic sea minimum. https://climate.nasa.gov/ vital-signs/arctic-sea-ice/

NASA (2021). Global temperature. https://climate.nasa.gov/vital-sig ns/global-temperature/

National Snow and Ice Data center (NSIDC). https://nsidc.org/cryos phere/glaciers/questions/climate.html (accessed March 25, 2021).

Neumann, B., Vafeidis, A., Zimmerman, J., and Nicholls, R. (2015). Future coastal population growth and exposure to sea-level rise and coastal flooding - A global assessment. PLOS One, 10(3), e0118571. https://doi.org/10.137/journal pane 0118571

Past Global Changes (2021). Pages overhead set. www.Yumpu.com/ en/document/read/37729130/pages (accessed March 2, 2021).

NOAA Office of Marine and Aviation Operations (2021). https: //www.omao.noaa.gov/find/media/images/image-licensing-usagein fo\#: :text=NOAA $\% 20$ still $\% 20$ images $\% 2 \mathrm{C} \% 20$ audio $\% 20$ files,co mputer\%20graphical\%20simulations $\% 20$ and $\% 20$ webpages.\&text $=$ This $\% 20$ general $\% 20$ permission $\% 20$ does $\% 20$ not,the $\% 20$ NOAA $\% 20 \mathrm{emblem} \% 20(\operatorname{logo})$ (accessed March 15, 2021).

Sen Roy, S. and Sen Roy, S. (2021). Spatial patterns of long-term trends in thunderstorms in India. Natural Hazards. 107(2), 15271540. https://doi.org/10.1007/s11069-021-04644-6

Shepherd, M. Three things people get wrong about the polar vortex and climate change. https://www.forbes.com/sites/marshallshepherd/ 2021/02/19/3-things-people-get-wrong-about-the-polar-vortex-and -climate-change/?sh=4c047e39426e (accessed January 21, 2021).

Royal Netherlands Meteorological Institute (2009). https://www.knmi. $\mathrm{nl} /$ kennis-en-datacentrum/achtergrond/linking-changes-in-hourlyprecipitation-extremes-to-the-clausius-clapeyron-relation

Rutter, N. and Baker, N. Glaciers in Canada. The Canadian Encyclopedia. (Last edited February 12018 )

Sassian, M. (2020). Colorado State University issues updated forecast for 2020 hurricane activity. https://www.iii.org/insuranceindustry blog/colorado-state-university-issues-updated-forecast-for-2020hurricane-activity/.

Schmith, T and Tonboe, R. (2009). The Frozen Sea: Climate and Climate Change. Aktuel Naturvidenskab, Denmark.

Scott, C. Zhang, F., and Mukherji, A. (2019). Water in the Hindu Kush Himalaya, The Hindu Kush Himalaya Assessment. Springer.

Statista. Unpredictable danger: Hurricane seasons since 1967. https:// www.statista.com/chart/11009/hurricanes-over-the-atlantic-basin/ (accessed March 21, 2021).

Taraky, Y., Gharabaghi, B., McBean, E., Liu, Y., Daggupati, P., and Shrestha, N. Hydrologic assessment of proposed large dams in the Kabul River Basin - Benefits, risks, policy implications. Water International, under review.

UN Population Division (2019). Probabilistic Population Projections Based on the World Population Prospects 2019. Mountain View, CA: Creative Commons.

Weisman, A. (2007). An earth without people. Scientific American, 297(1), 76-81. https://doi.org/10.1038/scientificamerican0707-76

Vergara-Temprado, J., Ban, N., and Schär, C. (2021). Extreme subhourly precipitation intensities scale close to the ClausiusClapeyron rate over Europe. Geophysical Research Letter, 48(3), e2020GL089506. https://doi.org/10.1029/2020GL089506 